\title{
Purpose, content, organizational principles of language teaching in primary school in Great Britain in the second half of the XX century
}

\author{
M. Cheveliuk \\ Open International UNIVERCITY of Human Development “UKRAINE”, Kiev, Ukraine \\ Corresponding author. E-mail: marianna.cheveliuk@gmail.com
}

Paper received 29.08.20; Accepted for publication 16.09.20.

\section{https://doi.org/10.31174/SEND-PP2020-236VIII94-04}

\begin{abstract}
At the beginning of the second half of the twentieth century in the UK there have been significant changes in society and the world at large. Before that, it concerned socio-political and technological aspects. The content of education, forms and methods of teaching at that time did not meet these requirements. All this was covered in numerous reports and publications by British teachers. They sought to overcome the tradition of underestimating the importance of pedagogical theory in solving practical issues of school activities, in connection with which considerable attention was paid to the analysis of curricula and programs and the study of school education.
\end{abstract}

Keywords: school education, curricula, teachers, research.

The purpose of the article identifies the content of education, forms and methods of teaching language education in primary school.

Materials and methods. In order to determine the content of education, forms and methods of teaching, research work of a practical nature, as well as theoretical research was conducted. The social level of primary school students was studied

Results and their discussion. In Britain, it was decided to reform the curriculum. Many features of the content of education were considered and studied.

In the practice of schools, a number of shortcomings were identified: 1) the exceptional attention paid to the teaching and "extraction" of ready-made information by students; 2) excessive specialization and lack of relationships between subjects; 3) academicism; 4) excessive pressure of exams on the content of education [2, p. 44-45].

The School Board for the Development of Curricula at the Ministry of Education and Science of England conducted research work of a practical nature. Local centers on the basis of school educational institutions also conducted similar practical research.

The shortcomings of school education reflected the underestimation of the role of active independent activity of students by teachers-analysts and contempt for factual knowledge by representatives of pedocentrism.

In school education, the purpose of learning was determined in accordance with the beliefs of the theoretical currents of scientists and teachers at that time. The main thing was to understand the nature of the educational process. The essence of learning was to reveal the innate abilities of the child, to accumulate individual experience, to discover knowledge. Much attention was also paid to external factors, such as the environment in which the pupils are.

According to pedocentrists, according to their understanding of the purpose of education, the curriculum is not a purposeful program of knowledge acquisition by students, but is a means of attracting them to culture in the broadest sense, with specific ways of such involvement and standards of knowledge standards [12, p. 7].

Representatives of the pedagogy of linguistic analysis and well-known educators K. Richmond, J. Kerr, D. Wheeler insisted on a clear specification of the formulation of the goals of curricula [7, p. 70].

According to scientists, it was determined that the general educational goals should take the form of special tasks, the solution of which should direct the activities of students. The most fundamental at that time were the cognitive goals, which were to form the basis on which to develop all other educational goals. In curricula, goals should be clearly grouped and interconnected, and this relationship should determine the sequence of learning content. Therefore, they believe that it is important to determine the structure and form of the relationships that exist between the goals.

Educators-analysts tried to identify separate, closely related elements of curriculum planning, contrasting such planning with the traditional in the country, which was based only on the content of educational material. P. Hirst identified three consecutive elements: 1) the goals of education (education of certain qualities of the mind, the acquisition of knowledge and skills, the development of values); 2) development of the program of various pedagogical types of activity necessary for achievement of the set educational purpose (character of teaching, excursions, discussions, exercises, laboratory works, etc.); 3 ) the content of educational material [8, p. 143].

In the 70's of the twentieth century. J. Kerr developed specific questions of the theory of curriculum planning in accordance with the system of educational goals in the United Kingdom. He built a model of the theory of the curriculum taking into account the psychological, pedagogical, social and philosophical aspects of education. The researcher believed that the theory of the curriculum can be divided into four interrelated elements: learning goals, knowledge, learning experience in school and curriculum evaluation [4, p. 20].

According to J. Kerr, pedagogical goals should be achieved through learning, indicating that each stage of the curriculum sets its own goals. Namely, the level of development of students, their needs and interests (psychological basis of the program); social living conditions of students and problems they may face (social basis); the nature of educational material and types of learning that may arise during the study of educational material (philosophical basis). J. Kerr noted that "the final selection and sequence of goals should be based on modern principles of learning" [4, p. 22]. 
In the field of knowledge, the scientist attached great importance to their integration, the rejection of artificially combined sets of information, consistency in the construction of training courses and in the repetition of the main elements of the curriculum. The experience of learning in school, he believed, covers the field of learning theory, which studies the forms and methods of learning, related to the psychological problem of individual characteristics of students, with issues of social pedagogy. In evaluating the curriculum, J. Kerr considered it necessary to use tests, interviews, observation methods, etc., which provide an opportunity to verify the results of educational goals and stressed the importance of developing new methods to assess each aspect of the curriculum. J. Kerr departed from the behaviorist approach in defining the goals of education and, attaching great importance to logical and philosophical (knowledge structure) and social factors, identified the activities of students and teachers in order to achieve specific educational goals.

During this historical period in the UK there was a search for new theoretical and pedagogical foundations of the educational process, due to the desire to increase the efficiency of the school as an educational institution in connection with the needs of politics, economics, technology and psychological and pedagogical relations. hereditary talent. The structural organization of secondary education and its content, in particular, the field of humanities, have undergone serious reforms [1].

The cycle of humanities belongs to the category of scientific disciplines, which is a leader in the school of socio-political, cultural, moral ideals of society. At the beginning of the second half of the century, the field of humanities education in Great Britain was in a state of crisis, which manifested itself in the inconsistency of humanities education with the requirements of the time. British educators saw the following inconsistency: a) in the unavailability of academic school courses for the masses; b) in the excessively conservative, traditional nature of history, literature, language courses in academic schools, their certain separation from real life; c) in the dominance of traditional teaching methods. Scientists J. Plumb, L. Stenhouse emphasized that "culture can no longer remain only a culture for the elect", "strengthening the power of reason as a goal of humanitarian education does not correspond to the objective socio-political realities of the time" [6; p. 7].

The influence of leading pedagogical currents was traced in the approaches to teaching the humanities. Representatives of the pedagogy of linguistic analysis advocated a clear logical system in the teaching of humanities, and representatives of pedocentrism advocated the modernization of the content of humanities education. R. Morris in teaching languages proposed to shift the center of gravity "from analysis to synthesis." He wrote: "When learning a language, emphasis should be placed on use: the ability to express one's own thoughts in words, to understand and to be understood, to write freely and creatively with imagination, and not to be captivated by grammar" [9, p. 2].

In order for humanities subjects to serve the purposes of general education, pedocentrists believed that the main thing in their teaching should not be mastering the system of knowledge, but developing students 'ability to "penetrate into the essence of things" based on students' own interests and experience [12, p. 102].

A group of influential teachers - W. Rove, A. Clegg, D. Holbrooke considered the problem from the point of view of "culture and education", understanding culture as "intellectual side of civilization" and insisted that students in the classroom should create their own microculture, seeing the possibility of developing microculture due to interest in learning [12, p. 9-10].

L. Stenhouse wrote that the teaching of humanities in modern secondary schools is best built not on a subject basis, but on a thematic basis and to study "not the body of factual knowledge, but the quality of human experience" [12, p. 138]. At the same time, the teacher had to enter the interests of students and first adapt to them. Thus, the scientist saw the task of the teacher in the enrichment of the microculture of the class, meaning the intellectual development and education of internal culture, raising the moral level. That is, he defended the possibility of developing children's creative abilities in a mainstream school.

The main feature of reforming the structure of secondary schools in the 60s of the twentieth century. was the organization of joint secondary schools, which was the main reason for the theoretical and practical work to develop the problem of the content of school education in the pedagogy of the country. Prior to that, according to the Education Act of 1944, the country had: grammar, technical (their number was only 1\%) and modern secondary schools.

In British grammar schools, the humanities prevailed traditionally. In the three junior classes, the curriculum was almost the same for all students (only Latin was not taught to all children) and included: English and literature, French and Latin, mathematics, history, geography, general social sciences, religion, music, fine arts, physical education, housekeeping for girls and wood and metalworking lessons for boys [1].

Gradually in the 50-70s of the twentieth century. grammar school curricula have become more flexible. The curriculum of the first and second year of study was the same and reflected the general picture of the work of students in a particular class, although it was followed by an individual schedule for each student and teacher. There were ample opportunities to combine subjects and, for example, the Department of Modern Languages made it compulsory to study mathematics so as not to deprive a person of the opportunity to enter a faculty of another profile if he changed his professional orientation and to promote general education. Although such inclusion of subjects of a completely different field of knowledge and profile has not become common practice.

Creation in Great Britain in the 60-70s of the twentieth century. a new type of secondary school - combined - has become a landmark event in school reform in the country. The process of formation of these schools was very complex and controversial. Initially, in the internal organization of the merged school, there was a tendency of mechanical unification under one roof of different types of high school: grammar, technical, modern.

The curricula of the first and second years of secondary school in the mid-1960s were generally close to the 
grammar school curriculum. The only difference was the greater attention to "Handicrafts" and in some schools from the first year of study taught drawings. In the third year of study, departments were introduced that corresponded to certain types of secondary schools that existed before. In the field of language education, the difference was that the students of the grammar department began to study the second and, to some extent, the third foreign language while reducing the amount of labor training. Students of other departments did not study the second and third foreign languages. The curriculum of the sixth grade had a lot in common with the curricula of grammar and technical schools [1].

In general, the modernization of the content of education was aimed at overcoming the age-old traditions of "classical education" in elite types of schools, on the one hand, and the elementary-practical approach to education in mainstream schools, on the other.

At the beginning of the second half of the twentieth century. British scholars, whose subject of interest was language learning, noted that "although the scientific approach in the field was formed in the late nineteenth century. with the development of linguistic disciplines and scientific research of pedagogical problems, only since then have consistent efforts been made to study the theory and practice of language pedagogy" [13, p. 54]. On the state of research on the theory and practice of language teaching at that time in the UK, researcher J. Carroll wrote: "There is a noticeable lack of research and a lack of research traditions. A review of articles published in the journal Modern Languages over the past 15 years shows that there are only a few articles that report the results of research. Most language learning publications are just messages about one's own experiences, expressing opinions or inviting to discussion. Many articles give the impression that their authors do not even follow the simplest rule of scientific work about the need to be aware of what their predecessors wrote or said about a particular problem or issue. The state of affairs in Britain can be described as follows: there is a significant amount of language learning experience, a significant amount of discussions, some experimental individual work, but there is no systematic research, such as can be traced in other areas of teaching [3, p. 128-129].

In the 60 s of the twentieth century. the state of affairs has changed dramatically. Interest in the scientific substantiation of the problems of language education, determining its place in the content of education has significantly increased. Scientific developments began to have a significant impact on the pedagogical practice of language teaching. One after another, language research centers appeared in foreign countries, international conferences on language teaching were held, the work on the development of educational materials expanded significantly, and the amount of information on language education increased. The growing influence of scientific and practical research in the 1960s was primarily explained by the research approach to resolving contradictions and debatable points in language teaching. The formation and active use in the 1950s of audio-linguistic and situational methods of language learning, the use of tape recorders, language laboratories, etc., aroused widespread interest in many countries and prompted the identification of their positive pedagogical traits and opportunities through empirical research. The difficulty in using the new teaching methods was that they were designed to teach adults the language and the possibilities of using them at the school level have not been properly explored. To solve this problem in the UK, a project of the Naffield Foundation and later the School Board were involved, which developed relevant courses in French, German, Spanish and Russian. However, most studies did not give the clear results expected of them, which led to an understanding of the need to study the fundamental issues of educational content, the nature of language learning, which was the focus of research and teachers in the 70's.

In the new conditions, teachers had to determine the purpose, content, methods of teaching foreign languages to students with different abilities, because in grammar schools, training was aimed at the most able and socially secure. Initially, the methods and forms of teaching developed by educational traditions in grammar schools were transferred to secondary schools, and then children with worse performance either did not learn a foreign language at all, or learned it to a much lesser extent. In most schools, it was decided to include a foreign language in the compulsory curriculum for students aged 11 to 14 for three years, after which the foreign language was classified as a subject of choice. Only a few (selected students) from the age of 12 or 13 could learn a second foreign language.

During the 70 s of the twentieth century. in the approach to teaching foreign languages there was a transition to language learning for the purpose of communication, knowledge of the language began to be considered as a means of communication with foreigners. Transformations in teaching methods were the abandonment of grammartranslation and direct methods that prevailed before the Second World War, and the widespread use of situational language learning with a gradual increase in emphasis on the development of oral and speech skills.

Issues of reforming language curricula were studied by M. Brin, C. Dodson, J. P. B. Allen, K. Brumfit, K. Kandlin, J. L. Clark. Scholars advocated a combination of elements of different pedagogical and linguodidactic concepts and suggested emphasizing both structural and communicative aspects in language teaching. G. Stern noted that most scholars and practitioners agreed that the curriculum (syllabus) is related to the definition of tasks, content and sequence. The main thing that traced the difference of views is the importance given to the methodological aspects of learning. Some educators believed that the theoretical and methodological aspects are an integral part of the curriculum, others, like G. Widdowson, removed them from the curriculum to give more freedom to teachers $[11$, p. 13].

In practice, three ways of curriculum structure were proposed: - "additional" (appendage approach), which provided for the mechanical addition of communicative dimension to existing curricula; - "developing" (build-up approach), in which the student moves from controlled learning under the guidance of a teacher to free communication; - "reversible" (reversible approach), according to which the curriculum, focusing on the formal and rhetorical features of language, is associated with a number of communicative activities, based on the acquisition of language knowledge and learning from 
experience [5, p. 104-105]. Moreover, researchers argued that when compiling a curriculum in any subject, including foreign languages, it is important to develop a model that would reconcile the objective socially recognized needs and individually outlined the subjective needs of students.

In the 70 s of the twentieth century. the decentralization of education in the UK has allowed individual teachers and groups of teachers to launch their own pilot curricula. Research teams in different parts of the country have developed curricula. In 1986, there were more than 80 such groups in the country. The result of their theoretical and practical research were certain models of curriculum formation. Thus, in the curriculum developed in York, the emphasis was on defining the tasks to be performed by the student (for example, buying postage stamps, souvenirs, etc.), while the linguistic dimension was not defined, the choice was left to teachers. The Oxford curriculum, published in 1978, included new categories such as consent, satisfaction, pity, needs, and contained clear requirements for the formation of students' vocabulary and expected learning outcomes: the curriculum is organized around 6 themes - "Travel, Visiting Cafe / Restaurant, Shopping, Accommodation, City, Personal Information and Communication ". Each topic was identified in terms of expected learning outcomes within what students should be able to say, read, understand on a particular topic. There was no grammatical component in the content of teaching, which was a manifestation of a conscious rejection of the dominance of grammar in language teaching and set the task of reassessing the meaning of grammar in the content of teaching, emphasizing the understanding of the grammatical component as secondary to is a means of transmitting the value being transmitted, not existing separately.

Analysis of scientific and pedagogical and methodological literature shows that in Great Britain in the second half of the twentieth century. Foreign language teachers faced 2 serious challenges: 1) the transition in education from the most able children to teaching classes to students with mixed abilities; 2) shifting attention in the priority of learning to the formation of oral speech activities.

In 1977, the report "Modern Languages in Comprehensive Schools" was published, based on a study of the activities of 83 schools in 40 different regional educational districts. The report, defending the importance of foreign language teaching in school education, showed that the challenges posed to the field of modern foreign language teaching by the educational reforms of the $1960 \mathrm{~s}$ and 1970s had not been addressed and needed further serious action at the national level. Among the shortcomings in the state of teaching foreign languages in secondary schools were: 1) lack of clarity and clarity in defining the purpose and objectives of education; 2) insufficient level of training course planning; 3) lack of appropriate approaches and methods in teaching less gifted students; 4) lack of attention to gifted students; 5) shortcomings in the management of department heads. However, certain shortcomings have inspired scientists and teachers to further seek effective ways to improve foreign language learning in school education.

The formation of the content of education was focused on the implementation of certain tasks that make sense outside the classroom, teaching methods were to become much more active. Learning success began to be viewed in terms of communication, rather than the desire to achieve grammatical correctness. A curriculum was developed, consisting of eight sections: 1) a list of situations and topics $(16)$; 2) language tasks on each topic of two levels of complexity - "basic" (basic) and "advanced" (higher); 3) language functions; 4) general concepts; 5) grammar section; 6) communicative strategies (ways of understanding unfamiliar lexical units); 7) lexical volume (defined thematically and in alphabetical order); 8) criteria for evaluating success (positive evaluation) [10, p. 31-32].

In the 80 s of the twentieth century. the field of foreign language teaching has attracted the attention of the Ministry of Education and Science. In 1987, Her Majesty's Inspectorate published Matters for Discussion in the Matters for Discussion series, which made it mandatory for all students between the ages of 11 and 16 to learn a foreign language in school and to learn a second foreign language from the age of 14. years. The first of these ideas later received legislative implementation with the adoption of the national curriculum, and the second was not supported and that time caused considerable resistance.

However, according to B. Page, the introduction of the national curriculum marked both the victory and defeat of those who studied foreign languages in England and Wales. Victory - because thanks to this decision for the first time in the history of the country it allowed all citizens to gain experience in learning a foreign language, as well as proclaimed and approved a communicative approach to language learning, defeat - because many issues remain unresolved [10, p. 33-34].

In 1991, an order to teach modern foreign languages, in accordance with the national curriculum, identified foreign languages that could be chosen by students for study as the first foreign language. If earlier, for historical, geographical, political, financial reasons, the main foreign language taught in the country's secondary education system was French, now the number of modern foreign languages has been significantly expanded, including the current languages of the Council of Europe. and some others - Danish, Dutch, Italian, Portuguese, French, German, Greek, Spanish, as well as Chinese, modern Hebrew, Hindi, Japanese, Russian, Turkish, Urdu, etc. This did not mean that the traditional choice of a foreign language to study on the principle of "French or French" was over. However, the new official government decision provided the legal basis and gave effect to the teaching of any of these languages, in the event of a decision by one of the schools. The study of pedagogical sources shows that politicians, teachers, schools advocated such an opportunity, but to address this issue required determination and a consistent line of government and appropriate economic conditions. And although government policy in the last decade of the twentieth century. in this aspect, supported diversification, these initiatives did not receive adequate material support, which led to a small rate of achievement of decisions.

In 1988-1990, the Ministry of Education and Science established and funded a pilot project to identify the diversity of languages offered in schools as a first foreign language in 10 local educational regions and, accordingly, funded the organization of language retraining programs at 
a number of colleges. so that more teachers can teach 2 foreign languages. Over time, these attempts at the official level were stopped and at the end of the century it depended largely on the schools themselves, how diverse the foreign languages they offered for study were.

Conclusions. The decentralization of the country's education system has contributed to widespread experimentation and the development of different curriculum models in the United Kingdom. In the new models of the foreign language curriculum, foreign language communication was chosen for the purpose of teaching. Changes in language teaching, in relation to their role in the education of the individual with an emphasis on the development of communicative competence have been manifested in all parts of the UK and reflected in defining the purpose of teaching, restructuring the content of teaching the discipline, term of discipline, diversification of foreign languages in education, etc. In practice, a number of national features - a limited period of study; rather low status of a foreign language as an academic discipline; lack of clarity and clarity in defining the purpose and objectives of training; lack of appropriate approaches and methods in teaching less gifted students; limited number of foreign languages offered for study; the place of English in the world - complicated the success of learning foreign languages at the school level. The introduction of the national curriculum was a significant event for the industry, as foreign languages were recognized as a basic component of the content of school education. Taking into account national peculiarities, it was determined that the school stage of education should teach children how to learn foreign languages using adequate methods and forms of learning.

\section{ЛITЕРАТУРА}

1. Кузнєцова, О.Ю. Теоретичні галузі педагогічного дослідження та мовної освіти в зарубіжній педагогіці // Педагогічні науки: зб. Наука. пр.: Суми: СДПУ ім. А. С. Макаренка, 2000. С. 118-126.

2. Лапчинская, В. Реструктуризация педагогического образования в Англии // Народное образование, 1986. № 5. C. 87.

3. Carroll, J.B. Wanted: a Research Basis for Educational Policy on Foreign Language Teaching // Harvard Educational Review, 1960. № 30. P. 128-140.

4. Changing the Curriculum / Ed. by Kerr J. - London: Routledge and Kegan Paul, 1968. P. 133.

5. Clark, J.L. Curriculum Renewal in School Foreign Language Learning// Oxford: Oxford University Press, 1987. P. 178.

6. Crisis in the Humanities / Ed. by J.H.Plumb// Harmondsworth: Penguin Books, 1966. P. 172.

7. Hirst, P., Peters, R. The Logic of Education// London: Routledge and Kegan Paul, 1970. P. 147.
8. Hirst, P. The Logic of the Curriculum // Journal of Curriculum Studies, 1969. Vol. 1, № 2. P. 141-155.

9. Morris, R. The Sixth Form and College Entrance// London: Routledge and Kegan Paul, 1969. P. 223.

10. Page, B. Modern Language Teaching/Learning in Secondary Schools in England and Wales / Curriculum Development in Modern Languages for European Understanding and Cooperation (Secondary Education 10-15/16) / Ed. By Ge Stocks, Eike Thurmann// Strasbourg: Council for Cultural Cooperation, 1994. P. 26-34.

11. Selection and Distribution of Contents in Language Syllabuses / D.Girard in cooperation with J. Courtillon, B.Page, K.Richterich// Strasbourg: Council of Europe Press, 1994. P. 114.

12. Stenhouse, L. Culture and Education// London: Nelson, 1971. P. 169.

13. Stern, H.H. Fundamental Concepts of Language Teaching// Oxford, New York: Oxford University Press, 1997. P. 582.

\section{REFERENCES}

1. Kuznatsova, O. Yu. Theoretical hallucinations of pedagogical pre-education and modern education in foreign pedagogy // Pedagogical sciences: zb. The science. pr.: Sumi: SDPU im. A.
S. Makarenka, 2000. P. 118-126.

2. Lapchinskaya, V. Restructuring of pedagogical education in England // Public education, 1986. No. 5. P. 87. 